\title{
Factors associated with maternal near-miss at Public hospitals of South-East Ethiopia: An institutional based cross-sectional study
}

Ashenafi Mekonnen ( $\sim$ ashemw@gmail.com )

Madda Walabu University

\section{Genet Fikadu}

Istituto di Ricovero e Cura a Carattere Scientifico Centro di Riferimento Oncologico della Basilicata

Kenbon Seyoum

Madda Walabu University Goba Referral Hospital School of Health Science Department of Midwifery

\section{Gemechu Ganfure}

Madda Walabu University Goba Referral Hospital School of Health Science Department of Midwifery

\section{Sisay Degno}

Madda Walabu University Goba Referral Hospital School of Health Science Department of Midwifery

\section{Daniel Atlaw}

Madda Walabu University Goba Referral Hospital School of Health Science Department of Midwifery Abebaw Nigussie

Addis Ababa University School of Medicine department of physiology

\section{Research}

Keywords: Maternal near miss, women, age at first marriage

Posted Date: January 17th, 2020

DOI: https://doi.org/10.21203/rs.2.21116/v1

License: (c) (i) This work is licensed under a Creative Commons Attribution 4.0 International License.

Read Full License

Version of Record: A version of this preprint was published at Women's Health on January 1st, 2021. See the published version at https://doi.org/10.1177/17455065211060617. 


\section{Abstract}

Background Maternal near-miss precedes maternal mortality and women are still alive indicating that the numbers of near misses occur more often than maternal mortality. This study aims to assess the prevalence of maternal near-miss and associated factors at public hospitals of Bale zone, Southeast Ethiopia.

Methods Facility-based cross-sectional study design was carried out from October 1, 2018, to February 28,2019 , among 300 women admitted to maternity wards. A structured questionnaire and checklist were used to collect data. Epi-info for data entry and statistical package for social science for analysis were used. The descriptive findings were summarized using tables and text. Adjusted odds ratio with $95 \%$ confidence interval and $p$-value $<0.05$ were used to examine the association between the independent and dependent variables.

Result The prevalence of maternal near-miss in our study area was $28.7 \%$. Being age less than 20 years, age of first marriage less than 20 years, having husband with primary school complete and being from rural residence are factors significantly associated with maternal near miss. The zonal health department in collaboration with the education department and Justice Office has to mitigate early marriage by educating the community about the impacts of early marriage on health.

\section{Plain English Summary}

The world health organization defined maternal near-miss as "a woman who almost dies but survives the complication which happened during pregnancy, childbirth or within 42 days after the end of pregnancy." Obstetrics related hemorrhages and pregnancy induced hypertension are the most important causes of maternal near-miss. The other essential issue is that the occurrence of long-term morbidities like renal failure, respiratory tract disorder, and sudden death within a year is high compared to the general population. Currently maternal near-miss morbidity and mortality are becoming a concern by more and more peoples because of their increased awareness. Therefore, auditing maternal near-miss plays important role for improving maternal health care service since the case of maternal near-miss are more prevalent than maternal death.

Maternal mortality rate and infant mortality rate are the indicators for the status of health care in a community. Because of this, maternal death is one of the most overwhelming events in obstetrics with extensive implications on both the family and obstetrics care providers involved. Therefore, women are at risk for this sudden and unexpected event occurring during pregnancy, childbirth and postnatal period. This indicates that the continuum of maternal morbidity begins with a normal healthy pregnancy and ends with death though maternal deaths are rare events. Most of the obstetrics complication can be preventable by providing timely and proper intervention. But near-miss cases share many characteristics with maternal mortality and can provide information regarding the obstacles to overcome after the onset of acute complication. 
Our current finding revealed that the prevalence of maternal near-miss is $28.7 \%$. Our study also identified age $<20$ years, age at first marriage $<20$ years, husbands educational status and residence are factors significantly associated with maternal near-miss.

\section{Background}

Maternal morbidity is defined as ill-health in a woman during pregnancy, irrespective of pregnancy site or duration, which is caused or aggravated by the pregnancy or its management, but which is not caused by accident or incident. This concept ranges from mild to severe maternal morbidity. Maternal near-miss (MNM) and potentially life-threatening conditions (PLTC) are included as severe maternal morbidity (SMM) [1].

The World Health Organization (WHO) Working Group on Maternal Mortality and Morbidity Classification modified three pre-existing separate definitions of MNM and defined it as one, "a woman who nearly died but survived a complication that occurred during pregnancy, childbirth or within 42 days of termination of pregnancy." Moreover, a severe maternal complication is defined as a potentially life-threatening condition occurring during the antepartum, intrapartum or postpartum period [1-3].

The disease-specific criterion to identify MNM which was developed by WHO based on five core diagnostic groups were used in this study; (1) hemorrhage leading to emergency hysterectomy, shock, coagulation or need two or more units of blood transfusion; (2) pregnancy-induced hypertension including pre-eclampsia and eclampsia with clinical or laboratory indication necessitating termination of pregnancy to save the life of women; (3) dystocia leading to uterine rupture and imminent uterine rupture due to prolonged obstructed labour or previous caesarean section; (4) infections causing hypothermia or hyperthermia or clear manifestation of infection and (5) anemia with hemoglobin level of less than $6 \mathrm{~g} / \mathrm{dl}$ or clear clinical sign of anemia [4].

Globally, every day around 800 women loses their life due to pregnancy-related causes which are easily preventable. In most Sub-Saharan African countries, the improvement of maternal health made sluggish progress. The estimated global maternal mortality rate in 2013 was 289,000 per year and from this, the Sub-Saharan African countries share the highest burden. Even though, the high maternal deaths are occurring within these countries, the exact figure for each center categorizes these events as rare. This leads to a reduced level of power to allow the studies to investigate the potential risk factors. In this situation, MNM can serve as a proxy for maternal death which could help to evaluate the quality of maternity care in certain health facilities [5].

In 2014 WHO report, indicated that nine million women are victimized by near-miss. Because of this, in low and middle-income countries specifically among the humblest women the burden of MNM is high [1$3,6]$. The magnitude of MNM ranges up to $0.04 \%$ using management-based criteria and as high as $15 \%$ using disease-specific criteria. Furthermore, the burden of this problem is worse among low and middleincome countries [7 8]. For instance, the incidence of MNM in Ethiopia ranges from 8-29\% [9-11]. This could emasculate the normal functioning of women [12]. Age of women above 35 years [13-15], being 
from rural residence, having an uneducated male partner [16], not having formal education or having low educational levels, and low socioeconomic status [17] were factors significantly associated MNM. Furthermore, lack of knowledge about danger sign during pregnancy, presence of first delay in decision making [18], having history of chronic hypertension and anemia $[9,19]$ and having previous caesarian section and/or abortion were significantly associated with MNM [15].

One of the major public health concerns globally including Ethiopia is maternal near miss. Therefore, for achieving the sustainable development goal 3 of target 1, reducing the incidence of MNM is crucial [20]. Besides, investigating the causes of MNM will benefit maternity care practitioners for providing quality care by enhancing the readiness of the facilities. Moreover, investigating MNM events rather than maternal death has the following merits; MNM is more common than maternal mortality, reviewing nearmiss yields more likely palpable evidence on the pathways that lead to severe maternal morbidity, since the women survived, examining the care received is less threatening to providers, we can learn from the women themselves since they can be witness and every near-miss case can be used as a free lesson and opportunity for improving maternity care. Therefore, this study intends to assess the prevalence of MNM and associated factors at public hospitals of Bale zone, Southeast Ethiopia.

\section{Material And Methods}

\section{Study design, population and sampling procedures}

A facility-based cross-sectional study design was carried out from October 1, 2018, to February 28, 2019 at three public hospitals of Bale zone namely Robe, Ginnir and Delomena. Bale zone is located in Southeast Ethiopia which is $435 \mathrm{Km}$ far from the capital city of Ethiopia.

All women who are admitted at the maternity units of the selected hospitals during pregnancy, childbirth or postpartum period are the source population. Whereas, all women who are admitted at the maternity unit of the selected hospitals during pregnancy, childbirth or postpartum period during the data collection period were the study population.

With the basic assumption of $95 \% \mathrm{Cl}, 5 \%$ margin of error and $23.3 \%$ proportion of $\mathrm{MNM}$ [11] a single population proportion formula was used to calculate the sample size. Then, by adding a $10 \%$ nonresponse rate, the final calculated sample size was 300 . The final sample were proportionally allocated across the three hospitals based on the annual caseloads admitted at maternity unity. Therefore, 115 samples were allocated to for Robe, 100 for Ginnir and 85 for Delomena hospitals. Finally, using a systematic random sampling method every $7^{\text {th }}$ interval the study participants were selected from all selected hospitals.

\section{Data collection tools and procedure}

Using a pre-tested structured questionnaire, data were collected using a face-to-face exit interview about demographic, personal, community, obstetric, administrative and care provider related variables. To 
diagnosis MNM the disease-specific criteria developed by WHO were used. Ten nurses were involved as a data collectors.

\section{Data quality assurance}

The questionnaires were designed and modified in English and then were translated to the local languages (Amharic and Afan Oromo). Then, translated back to English to ensure consistency of content. A pre-test was conducted at Goba referral Hospital on $5 \%$ of the sample. One day training was given to data collectors and supervisors. The supervisor was monitored the data collection process to assure the quality of data. Daily, the field supervisor checked the completeness of the collected data. Before data entry, the completeness, accuracy, and consistency of data were checked. Then, incomplete questionnaires were excluded from the analysis. Furthermore, data were entered into Epi Info, version 7.2, and checked for outliers. The interview was conducted privately. Patients' card was reviewed to determine the occurrence of MNM.

\section{Data processing and analysis}

The coded data were checked and cleaned by entering into Epi Info version 7.2.1 and exported to statistical package for social science (SPSS) version 21 for analysis. The descriptive part of the results was presented using tables, frequencies, mean, standard deviation and text. To present the analytic part of the findings, bivariate logistic regression analysis was done. Those variables with a significance level ( $p$-value) $<0.05$ in the bivariate analysis were entered into a multivariable logistic regression model for further analysis and to adjust the confounding factor. Adjusted odds ratio (OR) with $95 \%$ of $\mathrm{Cl}$ and significance ( $p$-value) $<0.05$ was used to examine the degree of association between the independent variables and MNM.

\section{Result}

Two hundred ninety six (296) women completed the interview making the response rate of $98.7 \%$.

\section{Socio-demographic variables}

From 296 study participants involved in the study, 240(81.1\%) women age is between 20-34 years with the mean age of 25.1( \pm 5.2$)$. Two hundred seventy $(91.2 \%)$ women are married, 188(63.5\%) are Oromo ethnic group and the majority of the study participants accounting $74.7 \%$ are housewives (Table 1 ). 
Table 1: Shows the distribution of socio-demographic characteristics of study participants in public hospitals of Bale Zone, 2019. 


\begin{tabular}{|c|c|c|}
\hline Variables & Frequency & Percentage (\%) \\
\hline \multicolumn{3}{|l|}{ Age of respondent } \\
\hline$<20$ Years & 41 & 13.9 \\
\hline 20-34 years & 240 & 81.1 \\
\hline$>34$ years & 15 & 5.1 \\
\hline \multicolumn{3}{|l|}{ Marital status of respondents } \\
\hline Married & 270 & 91.2 \\
\hline Single/Divorced/widowed & 26 & 8.8 \\
\hline \multicolumn{3}{|l|}{ The ethnicity of the respondents } \\
\hline Oromo & 188 & 63.5 \\
\hline Amhara & 88 & 29.7 \\
\hline Others & 20 & 6.8 \\
\hline \multicolumn{3}{|l|}{ Religion } \\
\hline Muslim & 129 & 43.6 \\
\hline Orthodox & 105 & 35.5 \\
\hline Protestant/Catholic & 62 & 20.9 \\
\hline \multicolumn{3}{|l|}{ Occupation of the respondents } \\
\hline Housewife & 221 & 74.7 \\
\hline Farmer & 18 & 6.1 \\
\hline Government employee & 17 & 5.7 \\
\hline Others * & 40 & 13.5 \\
\hline \multicolumn{3}{|l|}{ Educational status of women } \\
\hline Unable to read and write & 54 & 18.2 \\
\hline Able to read and write & 60 & 20.3 \\
\hline Primary school & 101 & 34.1 \\
\hline Secondary school & 50 & 16.9 \\
\hline Above secondary school & 31 & 19.5 \\
\hline \multicolumn{3}{|l|}{ Income of the women } \\
\hline Low & 61 & 20.6 \\
\hline Moderate & 165 & 55.7 \\
\hline
\end{tabular}




\begin{tabular}{|c|l|l|} 
High & 70 & 23.6 \\
\hline Husbands educational status & & \\
Unable to read and write & 49 & 16.6 \\
Able to read and write & 12 & 4.1 \\
Primary school & 81 & 27.4 \\
Secondary school & 103 & 38.8 \\
Diploma and above & 51 & 17.2 \\
\hline Residence area of the respondents & & \\
Rural & 157 & 53 \\
Urban & 139 & 47 \\
\hline Distance from health facility & & \\
$<10 \mathrm{~km}$ & 126 & 42.6 \\
$>10 \mathrm{~km}$ & 170 & 57.4 \\
\hline
\end{tabular}

Others $*=$ student, daily laborer merchant, private employee and unemployed.

\section{Obstetrics related variables}

About 233 (78.7\%) of our study participants were booked for antenatal care (ANC) service and 173 (58.4\%) were self-referred. From a total of 296 study participants, 211 (71.3\%) reported that the current pregnancy is planned and wanted whereas regarding parity 130 (43.9\%) of the participants were multiparous (Table2).

Table 2: Shows the distribution of obstetrics related variables in public hospitals of Bale Zone, Southeast Ethiopia, 2019. 


\begin{tabular}{|c|c|c|}
\hline Variables & Frequency & Percentage (\%) \\
\hline \multicolumn{3}{|l|}{ ANC history } \\
\hline Booked & 233 & 78.7 \\
\hline Not booked & 63 & 21.3 \\
\hline \multicolumn{3}{|l|}{ Number of ANC visit } \\
\hline First visit & 43 & 18.5 \\
\hline Second visit & 56 & 24.0 \\
\hline Third visit & 68 & 29.2 \\
\hline Fourth visit & 38 & 16.3 \\
\hline More than four visit & 28 & 12.0 \\
\hline \multicolumn{3}{|l|}{ Type of ANC visit } \\
\hline First visit & 44 & 18.9 \\
\hline Repeat visit & 189 & 81.1 \\
\hline \multicolumn{3}{|l|}{ Source of referral } \\
\hline Self-referred & 173 & 58.4 \\
\hline Health facility & 123 & 41.6 \\
\hline \multicolumn{3}{|l|}{ Type of pregnancy } \\
\hline Planned and wanted & 211 & 71.3 \\
\hline Others & 85 & 28.7 \\
\hline \multicolumn{3}{|l|}{ Parity of the women } \\
\hline Primiparous & 136 & 45.9 \\
\hline Multiparous & 130 & 43.9 \\
\hline Grand multiparous & 30 & 10.1 \\
\hline \multicolumn{3}{|l|}{ Gestational age } \\
\hline Unknown & 21 & 7.1 \\
\hline$<27$ weeks & 37 & 12.5 \\
\hline 28-36 weeks & 20 & 6.8 \\
\hline 37-42 weeks & 214 & 72.3 \\
\hline$>42$ weeks & 4 & 1.4 \\
\hline Duration of labor & & \\
\hline
\end{tabular}




\begin{tabular}{|c|l|l|} 
Less than 24 hours & 253 & 85.5 \\
More than 24 hours & 43 & 14.5 \\
\hline Type of complication & 14 & 4.7 \\
Obstructed labor & 26 & 8.8 \\
HDP & 30 & 10.1 \\
Abortion & 10 & 3.4 \\
Hemorrhage & 12 & 4.1 \\
Sepsis & 192 & 64.9 \\
No complication & 12 & 4.1 \\
Others & & \\
\hline Type of care providers & 55 & 18.6 \\
Specialist/ emergency surgeon & 206 & 69.6 \\
Midwife & 35 & 11.8 \\
\hline General practitioner & 238 & 80.4 \\
\hline Duration of hospital stay & 58 & 19.6 \\
Less than 7 days &
\end{tabular}

\section{Administrative and medical personnel related variables}

Out of 296 study participants, 8 (2.7\%) reported that there was a power supply problem during their hospital stay, 22 (7.4\%) encountered delay in decision making and 47(15.9\%) reported that there was a delay in receiving care (Table 3).

Table 3: Distribution of administrative and medical personnel related variables in public Hospitals of Bale zone, Southeast Ethiopia, 2019. 


\begin{tabular}{|c|c|c|}
\hline Variables & Frequency & Percentage $(\%)$ \\
\hline Presence of a power supply problem & & \\
\hline Yes & 8 & 2.7 \\
\hline No & 288 & 97.3 \\
\hline Lack of transportation & & \\
\hline Yes & 18 & 6.1 \\
\hline No & 278 & 93.9 \\
\hline Lack of lifesaving materials & & \\
\hline Yes & 12 & 4.1 \\
\hline No & 274 & 95.9 \\
\hline Availability of blood product & & \\
\hline Yes & 144 & 48.6 \\
\hline No & 152 & 51.4 \\
\hline Presence of delay in decision making & & \\
\hline Yes & 22 & 7.4 \\
\hline No & 274 & 92.6 \\
\hline Presence of delay in receiving care & & \\
\hline Yes & 47 & 15.9 \\
\hline No & 249 & 84.1 \\
\hline Presence of senior care provider & & \\
\hline Yes & 86 & 29.1 \\
\hline No & 210 & 70.9 \\
\hline
\end{tabular}

\section{Prevalence of maternal near-miss}

From the five parameters used to measure the occurrence of MNM 22(7.4\%), women encountered severe hemorrhage leading to shock. Also, 48 (16.2\%) of our study participants developed pregnancy-induced hypertension with a clinical or laboratory indicating termination of pregnancy to save the life of mothers. The overall prevalence of MNM is 85 (28.7\%) (Table 4). 
Table 4: Shows the prevalence of MNM in public hospitals of Bale Zone Southeast Ethiopia, 2019.

\begin{tabular}{|c|l|l|}
\hline Variables & Frequency & Percentage (\%) \\
\hline Severe hemorrhage & 22 & 7.4 \\
Yes & 274 & 92.6 \\
No & & \\
\hline Severe pre-eclampsia or eclampsia & 48 & 16.2 \\
Yes & 248 & 83.8 \\
No & & \\
\hline Dystocia & 8 & 5.1 \\
Yes & 288 & 94.9 \\
No & 15 & \\
\hline Sepsis & 281 & 94.9 \\
\hline Yes & & \\
No & 30 & 10.1 \\
Anemia with $<6 \mathrm{~g} /$ dl & 266 & 89.9 \\
\hline No & 211 & 71.3 \\
\hline The overall prevalence of maternal near-miss & & \\
\hline
\end{tabular}

\section{Factors associated with the prevalence of MNM}

In binary logistic regression analysis, those variables significantly associated were exported to multivariable logistic regression analysis to control confounding factors. Those variables significantly associated in binary logistic regression are age of respondent, age at first marriage, educational status, monthly income of the respondent, husband educational 
status, residence area, distance from the health facility, source of referral, type of care provider, lack of transportation and delay in receiving care. Finally, age of respondent, age at first marriage, husband's educational status, and residence area are factors significantly associated in multivariate analysis after adjusting confounding factors.

Those women age less than 20 years almost 4 times more likely to develop MNM compared to their counterparts ( $\mathrm{AOR}=3.72 ; 95 \% \mathrm{CI}: 2.68-7.11$ ). The odds of experiencing MNM is

almost 3 times more likely to encounter women with age at first marriage is less than 20 years compared to their counterpart $(\mathrm{AOR}=2.69 ; 95 \% \mathrm{CI}: 1.32-5.48)$. Women whose husband educated up to primary school are 1.26 times more likely to develop MNM compared to those husbands are educated up to diploma or above (AOR=1.26; 95\% CI: 1.08-2.92). Those women from rural areas are almost 2 times more likely to encounter MNM compared to those urban resident women (AOR=1.79; 95\% CI: 1.07-4.43) (Table 5).

Table 5: Bivariable and Multivariable logistic regression analysis of factors associated with the prevalence of MNM in public hospitals of Bale zone, Southeast Ethiopia, 2019. 


\begin{tabular}{|c|c|c|c|c|}
\hline \multirow[t]{2}{*}{ ables } & \multicolumn{2}{|c|}{ MNM } & \multirow{2}{*}{$\begin{array}{l}\text { Crude OR with 95\% } \\
\text { CI }\end{array}$} & \multirow{2}{*}{$\begin{array}{l}\text { Adjusted OR with 95\% } \\
\text { CI }\end{array}$} \\
\hline & Yes & No & & \\
\hline \multicolumn{5}{|l|}{ of respondent } \\
\hline$<20$ years & 10 & 31 & $3.54(1.02-12.24)$ & $3.72(2.68-7.11) *$ \\
\hline 20-34 years & 61 & 173 & 2.95(1.03-8.46) & $3.88(0.90-15.52)$ \\
\hline$>=35$ years & 8 & 7 & 1.00 & 1.00 \\
\hline \multicolumn{5}{|l|}{ at first marriage } \\
\hline$>20$ years & 44 & 82 & $1.69(1.02-2.81)$ & $2.69(1.32-5.48) *$ \\
\hline 20-34 years & 41 & 129 & 1.00 & 1.00 \\
\hline \multicolumn{5}{|l|}{ cational status } \\
\hline Unable to read and write & 22 & 32 & $0.22(0.07-0.70)$ & $1.14(0.21-6.06)$ \\
\hline Able to read and write & 29 & 31 & $0.16(0.05-0.51)$ & $1.26(0.25-6.24)$ \\
\hline Primary school & 21 & 80 & $0.56(0.18-1.79)$ & $2.92(0.64-13.33)$ \\
\hline Secondary school & 9 & 41 & $0.68(0.99-2.41)$ & $2.56(0.59-11.16)$ \\
\hline Diploma and above & 4 & 27 & 1.00 & 1.00 \\
\hline \multicolumn{5}{|l|}{ thly income of the } \\
\hline ondent & 24 & 37 & $0.17(0.07-0.44)$ & $0.38(0.11-1.30)$ \\
\hline Low & 54 & 111 & $0.23(0.10-0.53)$ & $0.69(0.22-2.13)$ \\
\hline Middle & 7 & 63 & 1.00 & 1.00 \\
\hline \multicolumn{5}{|l|}{ High } \\
\hline \multicolumn{5}{|l|}{ band educational status } \\
\hline Unable to read and write & 22 & 27 & $0.23(0.09-0.59)$ & $0.72(0.19-2.70)$ \\
\hline Able to read and write & 4 & 8 & $0.37(0.09-1.54)$ & $0.23(0.04-1.40)$ \\
\hline Primary school & 30 & 51 & $0.32(0.13-0.76)$ & $1.26(1.08-2.92)^{*}$ \\
\hline Secondary school & 21 & 82 & $0.76(0.30-1.78)$ & $0.72(0.24-2.16)$ \\
\hline Diploma and above & 8 & 43 & 1.00 & 1.00 \\
\hline \multicolumn{5}{|l|}{ sondents residence area } \\
\hline Rural & 60 & 97 & $0.36(0.21-0.61)$ & $1.79(1.07-4 . .43) *$ \\
\hline Urban & 25 & 114 & 1.00 & 1.00 \\
\hline
\end{tabular}




\begin{tabular}{|c|c|c|c|c|}
\hline $\begin{array}{l}<10 \mathrm{~km} \\
>10 \mathrm{~km}\end{array}$ & $\begin{array}{l}23 \\
62\end{array}$ & $\begin{array}{l}103 \\
108\end{array}$ & $\begin{array}{l}1.00 \\
0.39(0.23-0.67)\end{array}$ & $\begin{array}{l}1.00 \\
1.33(0.62-2.85)\end{array}$ \\
\hline \multicolumn{5}{|l|}{ rce of referral } \\
\hline Self-referred & 62 & 111 & $0.41(0.24-0.71)$ & $0.47(1.22-0.98)$ \\
\hline Health facility referred & 23 & 100 & 1.00 & 1.00 \\
\hline \multicolumn{5}{|l|}{ of care provider } \\
\hline Specialist/emergency & 20 & 35 & 1.00 & 1.00 \\
\hline Midwife & 48 & 158 & $1.65(0.70-3.91)$ & $2.04(0.82-5.11)$ \\
\hline General practitioner & 17 & 18 & $3.11(1.49-6.50)$ & $1.25(0.07-1.90)$ \\
\hline \multicolumn{5}{|l|}{ s of transportation } \\
\hline Yes & 12 & 6 & $0.18(0.06-0.49)$ & $0.06(0.01-1.33)$ \\
\hline No & 73 & 205 & 1.00 & 1.00 \\
\hline \multicolumn{5}{|l|}{ ty in diagnosing the } \\
\hline lem & 9 & 38 & $0.20(0.08-0.50)$ & $1.75(0.63-4.84)$ \\
\hline Yes & 76 & 173 & 1.00 & 1.00 \\
\hline No & & & & \\
\hline
\end{tabular}

NOTE: $*$ p value is significant at $\mathrm{p}<0.05 \quad 1.00=$ Reference for category

\section{Discussion}

The prevalence of MNM in our study area is $28.7 \%$ which is higher than the study done in developing countries ranging from $0.14-0.75$ [22-24]. Also, this finding is higher than the finding in middle-income countries accounting from 1.5-7.7\% [25-27]. This variation could be attributed because of sociodemographic variation, tools used to assess MNM and the presence of advanced technologies used to detect the occurrence of MNM early and intervene it.

A study done in Brazil indicated that the prevalence of MNM ranges up to $2.11 \%$ which is lower than the current findings and $3.2 \%$ in a university hospital of Syria $[14,26,28]$. This difference could be caused by the variation in socio-demographic characteristics and tools used to measure MNM.

The prevalence of MNM in Sub-Saharan African countries ranges from 2.21 to $12 \%$ which is lower than the current finding $[18,29-31]$. Majority of our study participants are from rural area were transportation access is difficult. Therefore, those women from rural area reaches at health facility after developing near-miss. This could attributes the variation in prevalence of maternal near-miss. 
The study conducted in central Uganda revealed that the MNM is $27 \%$ which is consistent with the current finding. This similarity could be attributed because of similar socio-economic status of the countries.

The study done in Amhara regional state referral hospital identified that the prevalence of MNM as $23.3 \%$ which is in line with our current finding. This similarity might be because of the same socio-demographic characteristic and tools used to measure the current finding [11].

Those women age less than 20 years had almost 4 times more likely to develop MNM compared to their counterparts $(\mathrm{AOR}=3.72 ; 95 \% \mathrm{Cl}: 2.68-7.11)$. This finding is contrary to the other study revealing that age above 35 years is a risk factor for MNM. This variation could be because in our study area there is a high prevalence of early marriage which can lead to high MNM $[13,15]$.

The odds of experiencing MNM is almost 3 times more likely to encounter women with age at first marriage is less than 20 years compared to their counterpart ( $\mathrm{AOR}=2.69 ; 95 \% \mathrm{Cl}$ : $1.32-5.48)$. This could be attributed because of the presence of early marriage that can result in an increased incidence of obstructed labor, cesarean section, pregnancy-induced hypertension, and others. This all can result in an increased incidence of MNM.

Women whose husband educated up to primary school are 1.26 times more likely to develop MNM compared to those husbands are educated up to diploma or above(AOR $=1.26 ; 95 \% \mathrm{Cl}$ : 1.08-2.92). This finding supports the study done by Mulugeta and others revealing that having an uneducated partner and having a low educational level are factors significantly associated with the occurrence of MNM [11].

\section{Conclusion}

The overall prevalence of MNM in our study area is high. Age less than 20 years, age at first marriage less than 20 years, attending less than secondary school and being from rural areas are factors significantly associated with the prevalence of MNM. Ministry of health in collaboration with different stakeholders has to mitigate early marriage by educating the community on its impact on women later life.

\section{Declarations}

\section{Ethic approval and consent to participate}

Ethical clearance was secured from the ethical review board of Madda Walabu University. Then, an ethical clearance letter was submitted to the respective hospitals. After obtaining permission from respective hospitals, the purpose of the study was explained to study participants and informed verbal consent was secured from them. Also, to assure the privacy and confidentiality of the information, participants name or address wasn't be recorded.

\section{Consent for publication}

Not applicable in this section 
Availability of data and materials

In the main paper all the available data and material used are presented and upon request data will be forwarded by corresponding authors.

\section{Competing interests}

The authors declare that they have no competing interests.

\section{Funding}

This survey was funded by Madda Walabu University but the funder has no role in designing, analysis, data interpretation and publication of the finding.

\section{Authors' contributions}

AM, GF, KS, GG, SD, DA and AN designed the study and were involved in drafting, statistical analysis and correcting the manuscript. All the authors read the manuscript, critically revised it for important intellectual content and approved the final version of the manuscript.

\section{Acknowledgments}

We would like to express our gratitude to Madda Walabu University for funding this research project. We would also like to extend our acknowledgment to the three hospitals for providing permission to conduct this survey. Finally, we would like to express our appreciation to our study participants for providing us with pertinent information.

\section{Authors' information}

${ }^{1}$ Madda Walabu University, Goba Referral Hospital, School of Health Science, Department of Midwifery, Bale Goba, Ethiopia

${ }^{2}$ Madda Walabu University, Goba Referral Hospital, School of Medicine, Department of Human Anatomy, Bale Goba, Ethiopia

${ }^{3}$ Addis Abeba University, School of Medicine, Department of Human Physiology, Addis Abeba, Ethiopia

\section{References}

1. Say L, Souza JP, Pattinson RC. Maternal near miss-towards a standard tool for monitoring quality of maternal health care. Best practice \& research Clinical obstetrics \& gynaecology. 2009;23(3):287-96.

2. Pattinson R, Say L, Souza JP, Broek Nvd, Rooney C. WHO maternal death and near-miss classifications. Bulletin of the World Health Organization. 2009;87:734-A. 
3. Souza JP, Cecatti JG, Haddad SM, Parpinelli MA, Costa ML, Katz L, et al. The WHO maternal nearmiss approach and the maternal severity index model (MSI): tools for assessing the management of severe maternal morbidity. PloS one. 2012;7(8):e44129.

4. Say L, Pattinson RC, Gülmezoglu AM. WHO systematic review of maternal morbidity and mortality: the prevalence of severe acute maternal morbidity (near miss). Reproductive health. 2004;1(1):3.

5. Organization WH, Unicef. Trends in maternal mortality: 1990 to 2013: estimates by WHO, UNICEF, UNFPA, The World Bank and the United Nations Population Division. 2014.

6. Lozano R, Wang H, Foreman KJ, Rajaratnam JK, Naghavi M, Marcus JR, et al. Progress towards Millennium Development Goals 4 and 5 on maternal and child mortality: an updated systematic analysis. The Lancet. 2011;378(9797):1139-65.

7. Tunçalp Ö, Hindin MJ, Souza J, Chou D, Say L. The prevalence of maternal near miss: a systematic review. BJOG: An International Journal of Obstetrics \& Gynaecology. 2012;119(6):653-61.

8. Maswime S, Buchmann E. A systematic review of maternal near miss and mortality due to postpartum hemorrhage. Int J Gynaecol Obstet. 2017;137(1):1-7.

9. Liyew EF, Yalew AW, Afework MF, Essén B. Incidence and causes of maternal near-miss in selected hospitals of Addis Ababa, Ethiopia. PloS one. 2017;12(6):e0179013.

10. Gedefaw M, Gebrehana H, Gizachew A, Taddess F. Assessment of maternal near miss at Debre Markos referral hospital, Northwest Ethiopia: five years experience. Open Journal of Epidemiology. 2014;4(04):199.

11. Dile M, Seyum T. Proportion of maternal near misses and associated factors in referral hospitals of Amhara regional state, Northwest Ethiopia: institution based cross sectional study. Gynecol Obstet (Sunnyvale). 2015;5(308):2161-0932.1000.

12. Reichenheim ME, Zylbersztajn F, Moraes CL, Lobato G. Severe acute obstetric morbidity (near-miss): a review of the relative use of its diagnostic indicators. Archives of gynecology and obstetrics. 2009;280(3):337-43.

13. Goffman D, Madden RC, Harrison EA, Merkatz IR, Chazotte C. Predictors of maternal mortality and near-miss maternal morbidity. Journal of Perinatology. 2007;27(10):597.

14. Souza J, Cecatti J, Parpinelli M, Sousa M, Lago T, Pacagnella R, et al. Maternal morbidity and near miss in the community: findings from the 2006 Brazilian demographic health survey. BJOG: An International Journal of Obstetrics \& Gynaecology. 2010;117(13):1586-92.

15. Dias MAB, Domingues RMSM, Schilithz AOC, Nakamura-Pereira M, Diniz CSG, Brum IR, et al. Incidence of maternal near miss in hospital childbirth and postpartum: data from the Birth in Brazil study. Cadernos de saude publica. 2014;30:S169-S81.

16. Nansubuga E, Ayiga N, Moyer CA. Prevalence of maternal near miss and community-based risk factors in Central Uganda. International Journal of Gynecology \& Obstetrics. 2016;135(2):214-20.

17. Rulisa S, Umuziranenge I, Small M, van Roosmalen J. Maternal near miss and mortality in a tertiary care hospital in Rwanda. BMC pregnancy and childbirth. 2015;15(1):203. 
18. Adeoye IA, Onayade AA, Fatusi AO. Incidence, determinants and perinatal outcomes of near miss maternal morbidity in Ile-Ife Nigeria: a prospective case control study. BMC pregnancy and childbirth. 2013;13(1):93.

19. Mbachu II, Ezeama C, Osuagwu K, Umeononihu OS, Obiannika C, Ezeama N. A cross sectional study of maternal near miss and mortality at a rural tertiary centre in southern nigeria. BMC pregnancy and childbirth. 2017;17(1):251.

20. Assembly G. sustainable Development goals. SDGs), Transforming our world: the. 2015;2030.

21. Witteveen T, Bezstarosti $H$, de Koning I, Nelissen E, Bloemenkamp KW, van Roosmalen J, et al. Validating the WHO maternal near miss tool: comparing high-and low-resource settings. BMC pregnancy and childbirth. 2017;17(1):194.

22. Murphy CM, Murad K, Deane R, Byrne B, Geary MP, McAuliffe FM. Severe maternal morbidity for 2004-2005 in the three Dublin maternity hospitals. European Journal of Obstetrics \& Gynecology and Reproductive Biology. 2009;143(1):34-7.

23. Donati S, Senatore S, Ronconi A, Group RMMW. Obstetric near-miss cases among women admitted to intensive care units in Italy. Acta obstetricia et gynecologica Scandinavica. 2012;91(4):452-7.

24. Ghazal-Aswad S, Badrinath P, Sidky I, Safi TH, Gargash H, Abdul-Razak Y, et al. Severe acute maternal morbidity in a high-income developing multiethnic country. Maternal and child health journal. 2013;17(3):399-404.

25. Siddiqui SA, Soomro N, Hasnain F. Severe obstetric morbidity and its outcome in patients presenting in a tertiary care hospital of Karachi. JPMA-Journal of the Pakistan Medical Association. 2012;62(3):226.

26. Almerie Y, Almerie MQ, Matar HE, Shahrour Y, Al Chamat AA, Abdulsalam A. Obstetric near-miss and maternal mortality in maternity university hospital, Damascus, Syria: a retrospective study. BMC pregnancy and childbirth. 2010;10(1):65.

27. Moraes APP, Barreto SM, Passos VMA, Golino PS, Costa JA, Vasconcelos MX. Incidence and main causes of severe maternal morbidity in São Luís, Maranhão, Brazil: a longitudinal study. Sao Paulo Medical Journal. 2011;129(3):146-52.

28. Litorp $H$, Kidanto HL, Rööst $M$, Abeid M, Nyström L, Essén B. Maternal near-miss and death and their association with caesarean section complications: a cross-sectional study at a university hospital and a regional hospital in Tanzania. BMC pregnancy and childbirth. 2014;14(1):244.

29. Ali AA, Khojali A, Okud A, Adam GK, Adam I. Maternal near-miss in a rural hospital in Sudan. BMC pregnancy and childbirth. 2011;11(1):48.

30. Nelissen EJ, Mduma E, Ersdal HL, Evjen-Olsen B, van Roosmalen JJ, Stekelenburg J. Maternal near miss and mortality in a rural referral hospital in northern Tanzania: a cross-sectional study. BMC pregnancy and childbirth. 2013;13(1):141.

31. Tunçalp Ö, Hindin MJ, Adu-Bonsaffoh K, Adanu RM. Assessment of maternal near-miss and quality of care in a hospital-based study in Accra, Ghana. International Journal of Gynecology \& Obstetrics. 2013;123(1):58-63. 